\title{
Application Strategies of Digital Technology in the Teaching of Interior Design
}

\author{
Linzi She* \\ Chongqing Energy College, Chongqing 402260, China \\ *Corresponding author: Linzi She, 329384946@qq .com
}

\begin{abstract}
With the rapid development and progress of science and technology, computer information technology is widely used by all walks of life and it involves all aspects in life. In recent years, with the advent of the information age, it has brought certain development opportunities to the teaching of interior design in China. Digital technology has been introduced into the teaching of interior design, thus changing the original teaching mode and content, in order to improve the teaching quality and efficiency of the interior design specialty. This article mainly analyzes the application and advantages of digital technology in the teaching of interior design, and suggests application strategies in this context, hoping to provide reference to relevant personnel.
\end{abstract}

Keywords: Digital technology; Interior design; Teaching; Application

Publication date: October 2021; Online publication: October 29, 2021

\section{Introduction}

The 21st Century Higher Education Reform Plan has clearly put forward the fundamental goal of the educational reform, which is to reform and innovate the training mode, build a scientific and reasonable curriculum system and structure, and improve the educational content and teaching system in combination with advanced cultural ideas as well as scientific and technological means, so as to promote the implementation of modern educational ideas. Practical results have shown that the application of digital technology in the teaching of interior design can promote the change of teaching concepts and teaching modes. It is the inevitable trend in the teaching development of the interior design specialty. The application of digital technology expands the scope of students' acceptance toward knowledge, helps students to examine the teaching content from a new perspective, and lays a foundation for the realization of new teaching methods and means.

\section{Analysis on the current situation of applying digital technology in the teaching of interior design}

At this stage, the integration of digital technology into the teaching of interior design is an inevitable trend in its educational development. Digital technology creates convenience for the cultivation of innovative talents by virtue of its strong energy and broad space for expansion.

At present, most interior designers use basic modeling software, such as 3ds Max and SketchUp, in combination with 720 degrees cloud rendering, Lumion, and VR (virtual technology) technology to realize digitization in completing their interior design schemes. There are several design software applications which are not professional, resulting in a "fast food" type situation in the field of interior design. In addition, with the continuous development of the interior design industry, many people have chosen to engage in this kind of work, leading to a fierce competition in the industry. Moreover, some companies are meeting the market demand just to obtain economic benefits, thus resulting in uneven design quality ${ }^{[1]}$. The causes of 
these problems are related to the interior design education. From the actual teaching situation of interior design, there are mainly two influencing factors. First, the curriculum is divorced from the market, where the contents have not been updated or adjusted. This means that the teaching contents are not keeping pace with the changes of the times. In addition, the teachers are facing difficulties in adapting to the development of the times. All these would definitely affect students' employment in the future. Second, the teaching effect and target cannot reach the standard requirement. In order to meet the needs of the market development, schools are excessively emphasizing on theoretical courses, hoping that students can quickly complete their studies and begin operating their designs immediately. However, this neglects the cultivation of their designing skills.

\section{Analysis on the advantages of applying digital technology in the teaching of interior design}

At present, the application and effect of digital technology have been widely valued by all walks of life. With the application of primary digital technology in the teaching of interior design, the development and updating of information technology and digital software have been promoted. In addition, the gradual application of digital software has brought interior design drawings closer to reality. In the teaching process, the primary task is for students to sort out clear design ideas and improve the details in those ideas. Thereafter, students are usually requested to use basic modeling software, such as 3ds Max and SketchUp, to build their design framework. Finally, they would have to use the 720 degrees cloud rendering technology to present the indoor design. Then, details such as lightings and switches would be added to the design in order for it to look more realistic. By using this design method, students can effectively avoid mistakes in plane drawing. The application of digital technology in the teaching of interior design provides an opportunity for students to expand their thinking, strengthen the cultivation and improvement of their operation skills, as well as accumulate design experiences ${ }^{[2]}$. The integration of art and digital technology in interior design can realize the concretization and visualization of abstract concept. This is conducive to the communication and exchange between teachers and students. With the integration, the disadvantages existing in traditional teaching would also be revealed in a timely manner, eventually leading to the most ideal teaching effect.

The application of digital technology adds a modern sense to interior design. However, this does not mean that manual drawing should be annihilated completely. The combination of digital technology with manual drawing can continuously improve the quality and efficiency of teaching, give full play to its advantages, abandon its shortcomings and defects, and lay a foundation for students to master professional knowledge.

\section{Application strategies of digital technology in the teaching of interior design}

\subsection{Cloud rendering platform}

As the most basic link of interior design, design has certain abstraction and complexity. It is difficult for students to understand the meaning only by relying on their own perception. This forms an obstacle for students during lessons. However, the application of digital technology in the teaching of interior design can solve this problem. Cloud rendering platform, as a new design software under the current internet mode, advocates the concept of cloud sharing. A designer can directly log into the cloud rendering platform website using a browser or client and then complete the construction and design of his or her spatial model through the massive design resources on the cloud rendering platform. At the same time, the cloud rendering platform is able to realize a 720 degrees spatial panoramic roaming mode and VR real scene mode. The rendering effect generates two-dimensional code, and visitors can directly look at the spatial design panoramic roaming scheme through their mobile phone or personal computers (PC), thus breaking the 
traditional two-dimensional design mode. For example, in the teaching of residential interior design, the cloud rendering platform provides rich information and design resources of real estate types, so designers can search for information first to generate ideas before designing. Besides, 3ds Max and SketchUp modeling and rendering can be completed in the design, and the modeling can be done directly on the cloud server. The design can then be shared with visitors or learners in the form of two-dimensional code ${ }^{[3]}$.

\subsection{VR technology}

It is an inevitable trend in the reform of art education to introduce virtual reality technology into the teaching of interior design. VR technology is applicable to students at different stages. For freshmen, teachers should not only teach students basic theoretical knowledge, but also the application methods of VR software so that students can use the software to experience on-site construction situation during classes. For sophomores, when imparting professional knowledge, such as 3ds Max modeling, SketchUp modeling, ergonomics, and other topics, teachers should first allow students to use the software to complete the basic modeling and then introduce the model into the VR scene, so that students can experience their own design results and modify their dissatisfaction in time. For example, in the teaching of commercial space design, teachers can divide the students into 3-5 groups and then provide each group with the design requirements and plans of shopping mall buildings and commercial space. The students should then conduct their own research and discuss among their group members to complete the design of the whole process: frame drawing - graphic design drawing - three-dimensional effect drawing - 360 degrees scene roaming drawing - VR virtual sample room design drawing display, within a specified time. This process does not only exercise students' team cooperation skills, but also teach them to solve practical problems encountered in designing ${ }^{[4]}$.

\subsection{Innovating the application of indoor related software to create conditions for the application of digital technology}

The application of digital software has created a large number of visual elements for students. Only by constantly studying these elements can they find the source of inspiration. In addition, in $3 \mathrm{ds}$ Max and SketchUp, data archiving can be carried out by means of cloud technology. This is beneficial in actual teaching and practical operation, and it also plays a very important role in the teaching of interior design.

In the process of interior design, combining the advantages of 3ds Max, SketchUp, 720 degrees cloud rendering, Lumion, and VR technology, the communication of service channels can be realized, thus providing great convenience for designers to observe the effect of design scenes from any angle without time and space constraints. Since Lumion does not have modeling capabilities, designers need to build their models using 3ds Max and SketchUp first and then, render them by Lumion software. Lumion software comes with a Chinese software interface, which is much easier to operate compared to English software interface.

\section{Conclusion}

In conclusion, as interior design is an art education, its design form has a certain abstraction and logic, thus having high requirements for innovative thinking and aesthetic judgment. In the teaching of interior design, through the form conversion of space module, the creation of digital thinking training module, and the design of digital software, the application of digital technology realizes the joint use of relevant software and improves the logical thinking ability as well as the design ability of the setter. This is conducive for a more comprehensive understanding of three-dimensional space model, and this would eventually promote the healthy development of the interior design industry. 


\section{Disclosure statement}

The author declares that there is no conflict of interest.

\section{References}

[1] Lu R, 2019, Practice Research of Digital Application in Teaching of Interior Design Specialty in Vocational Colleges. Fine Arts Literature, (10): 99-100.

[2] Yuan Y, 2021, How to Use Digital Technology to Promote the Teaching Reform of "Public Space Design" Course in Vocational Interior Design. Consumption Guide, (5): 94-95.

[3] Chen X, 2013, Practice Analysis of Promoting Teaching Reform of "History of Chinese and Foreign Architecture" Course in Interior Design Major of Higher Vocational Colleges by Using Digital Technology. Beauty and Times: Creativity (I), (12): 137-139.

[4] Su LP, Liu HL, 2018, Analysis on the Application of Digital Technology in Interior Design Teaching. Architecture Engineering Technology and Design, (34): 1051. 